\title{
The effects of CS intensity upon learning and performance of the conditioned eyelid response in monkeys ${ }^{\prime}$
}

R. R. MOURANT ${ }^{2}$ AND H. S. PENNYPACKER, DEPARTMENT OF PSYCHOLOGY AND CENTER FOR NEUROBIOLOGICAL SCIENCES, UNIVERSITY OF FLORIDA, Gainesville, Florida 32601

A replication of the design reported by Grice \& Hunter (1964) was performed using squirrel monkeys as Ss. In addition, extinction data were collected under a factorial design wherein groups trained to a single intensity $C S$ were subdivided at the beginning of extinction and half of each group shifted to the other value of CS intensity. The results indicate that the within-Ss procedure leads to inferior learning as well as acquisition performance and the learning is superior in the presence of a single soft $C S$ as opposed to a single loud $C S$.

In their discussion of a recently reported result concerning the interstimulus interval function governing eyelid conditioning in monkeys, Pennypacker \& Cook (1967) suggest that, within the range of stimulus intensities generally found suitable for human Ss, an inverse function may exist relating the intensity of an auditory CS to level of conditioning in monkeys. Such thinking is consistent with the theorizing of Sokolov (1963) who asserts that as stimulus intensity increases, the natural orienting response tends to be replaced by a defense reaction. Since part of the defense reaction of monkeys might be described as a wide-eyed stare, the effect of an intense CS on the probability of lid closure becomes obvious.

The widely cited experiment by Grice \& Hunter (1964), while showing that a within-Ss design is better able to detect CS intensity effects than is a between-Ss comparison, unfortunately shed no light on the question of whether the enhanced effect of CS intensity is primarily upon learning, performance, or both. Since monkeys exhibit considerably greater resistance to extinction in the eyelid conditioning situation than do humans, (Hilgard \& Marquis, 1936; Pennypacker \& Cook, 1967) it is possible to examine this question by extending the Grice and Hunter procedure into a factorial analysis of the extinction data obtained from monkey Ss.

The present experiment, then, had two objectives: (1) to determine the direction of the relationship between CS intensity and conditioning performance in wild monkeys, and (2) to determine whether such an intensity effect, whether obtained under a within-Ss or between-Ss design, is upon learning, performance, or both.

Subjects. Sixteen young adult male jungle born squirrel monkeys (Saimiri Sciurea) served as Ss.

Design. The acquisition phase of the experiment replicated the Grice and Hunter design. Four animals (Group S) were conditioned to a soft auditory CS, four (Group L) were conditioned to a loud CS, and the remaining eight (Group M) received a mixed random sequence of the two. In extinction, the two groups which had received a single value of $C S$ intensity during acquisition were subdivided; half the Ss in each group were switched to the other value of CS intensity (Groups L-S and S-L) while the remaining two animals in each group (Groups L-L and S-S) were extinguished in the presence of the same CS they had received in acquisition. The eight animals who had received a mixed sequence of loud and soft CSs during acquisition were divided into three groups for extinction: four of the animals continued to receive the mixed sequence, (Group M-M), two were shifted to soft only (Group $M-S)$ and the remaining two were shifted to loud only (Group M-L).

Apparatus. The apparatus and general procedure have been described in detail elsewhere (Pennypacker et al, 1966). Briefly, about two weeks prior to experimentation, three small plastic posts were surgically attached to the skull of each $\mathrm{S}$. Prior to each recording session, a circular platform which supported a microtorque potentiometer and the UCS delivery system was attached to these posts. The arm of the potentiometer was linked mechanically to the monkey's eyelid by a length of 5-0 surgical wire hooked to a small square of surgical cloth. A drop of flexible collodion secured the cloth patch to the anterior margin of the superior surface of the monkey's right eyelid. Movements of the potentiometer arm were transformed into voltage changes which were amplified and ink-written on a moving paper record by a Grass Model 5 Polygraph.

The CS was a $1000-\mathrm{Hz}$ tone delivered at either $60 \mathrm{~dB}$ (soft) or $90 \mathrm{~dB}$ (loud) by a Hewlett-Packard audio-oscillator through a $5 \mathrm{in}$. speaker mounted on the wall above and in front of $S$.

The UCS was a puff of air delivered at an intensity of 4.0 psi to the corner of the right eye through a 15 gauge square-end hypodermic needle. The duration of the UCS was $10 \mathrm{sec}$.

The CS-UCS interval was $3.0 \mathrm{sec}$ with the offset of the CS coinciding with the onset of the UCS. The relatively long interstimulus interval was chosed in an attempt to maximize attensity effects produced by the differential CS intensities. The intertrial interval ranged from 10 to $30 \mathrm{sec}$ with a mean of $20 \mathrm{sec}$. Grason-Stadler programming equipment controlled all event durations and interevent intervals.

During data collection, $S$ was restrained in a modified primate chair which was placed in a sound-deadened cubicle. $S$ was visually monitored through one-way glass from an adjoining room which housed the programming and recording equipment.

Procedure. Prior to each recording session, each $\mathbf{S}$ was briefly anesthetized with nitrous oxide and placed in the primate chair. In no case were the effects of the anesthetic discernible after $30 \mathrm{sec}$. All Ss received 200 paired CS-UCS trials (Ss in the mixed group received 100 trials at each CS intensity) and 120 extinction trials in which the UCS was omitted entirely. On Days 1 and 2, each S received 80 conditioning trials followed on Day 3 by an additional 40 paired trials and 40 extinction trials. On Day 4 , each $S$ received 80 extinction trials. The regular $24 \mathrm{~h}$ interruption during the course of extinction thus provides an opportunity to examine the effects of the major variables upon spontaneous recovery. The random order of CS presentation for the mixed group was restricted so that no more than four consecutive CSs were of the same intensity and equal number of loud and soft CSs occurred in each block of 20 trials.

Results and Discussion. A conditioned response was defined as any deflection in the ink-written record in the direction of closure which exceeded $1 \mathrm{~mm}$ provided that its latency exceeded 150 msec and that the closure was followed within $100 \mathrm{msec}$ by a deflection in the opposite direction. The latter criterion was imposed in order to avoid scoring as CRs deflections accompanying a downward shift of gaze.

A comparison of the results of the acquisition phase of the experiment with the Grice and Hunter data is presented in Fig. 1. Of principal interest is the failure of the present experiment to

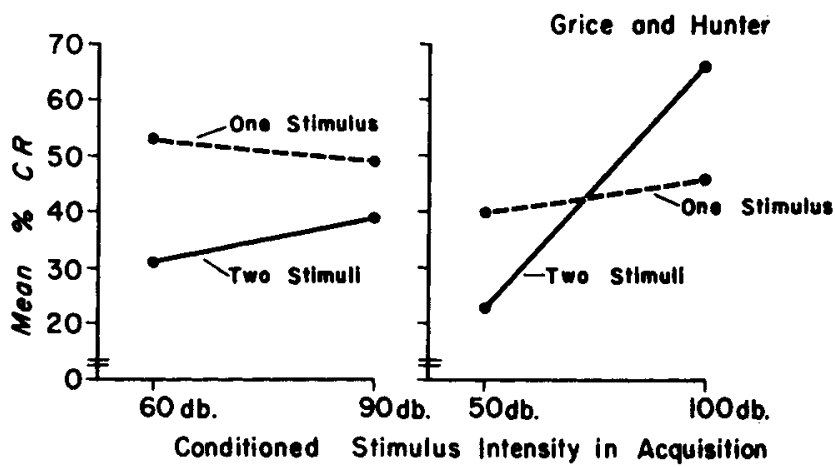

Fig. 1. Acquisition performance as a function of CS intensity compared with the results of Grice and Hunter. 


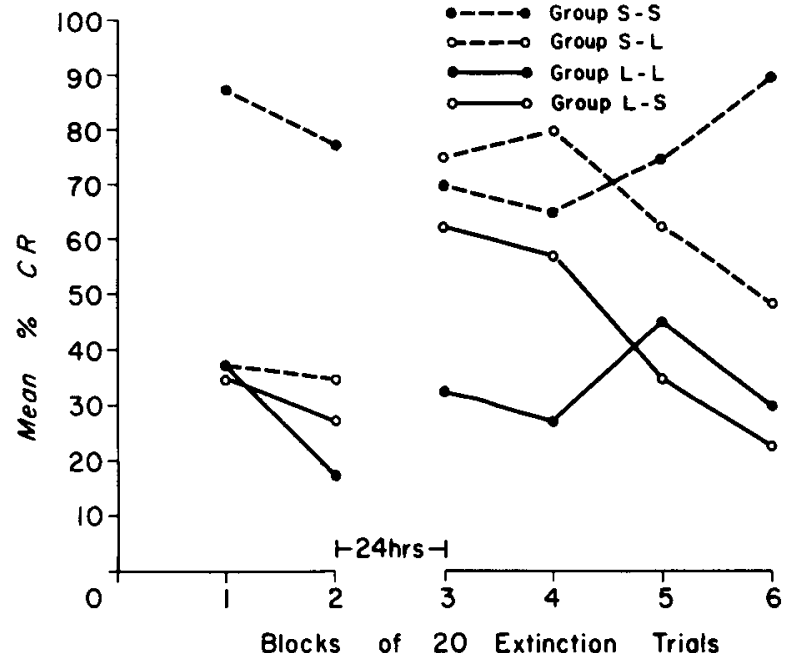

Fig. 2. Extinction performance of the groups comprising the single stimulus factorial subexperiment.

replicate the Design by Intensity interaction of Grice and Hunter while, on the other hand, showing a superiority of the single stimulus groups to the Mixed Group ( $F=6.124$, df $=1 / 14, p<$ .05 ), not found in the Grice and Hunter results. No other comparisons achieved statistical reliability. In the acquisition data, then, one finds little support for the expectation that an increase in CS intensity would have a deleterious effect on the conditioning performance of wild monkeys.

Consideration of the superiority of Groups $L$ and S to Group M suggests an explanation for the failure to produce a design by intensity interaction. If one supposes that the monkeys in Group $M$ failed to establish a functional equivalence between the two CS intensities, it follows that these animals learned two different, independent habits, each incurring only half the reinforcement of the single habit acquired by an animal in either Group L or Group S. Such complete differentiation of the two CSs would preclude the operation in monkeys of a contrast-with-adaptation-level phenomenon as proposed by Grice and Hunter to account for their large within-S effect. It is of passing interest that Grice and Hunter observed nearly equal performance under their two design conditions when their data were collapsed across stimulus intensity.

Some support for the assertion that superior learning occurred in the presence of a constant intensity $\mathrm{CS}$ is found by comparing the extinction performance of Groups $S$ and $L$ combined with that of Group $M$; the inferiority of Group $M$ persists throughout extinction although the effect falls short of significance, $(F=4.10$, $\mathrm{df}=1 / 14, \mathrm{p}<.10$ ).

The extinction data of the factorial subexperiment involving Ss who received one CS intensity during acquisition is presented in Fig. 2. The apparent superiority of the groups trained in the presence of a soft $\mathrm{CS}$ is highly reliable, $(\mathrm{F}=22.816, \mathrm{df}=1 / 14, \mathrm{p}<$ .01 ). Thus, greater learning apparently did occur in the presence of the soft CS although it was not particularly noticeable in the acquisition data. The effect of CS intensity on performance during extinction approached significance, $(F=5.181$, df $=1 / 14, p<$ .10 ), but this effect is probably due in large measure to the failure of Group S-S to show an appreciable degree of extinction within the 120 allotted trials.

The three way interaction of CS intensity during acquisition, CS intensity during extinction, and extinction trial blocks is also reliable, $(F=2.956, \mathrm{df}=5 / 20, \mathrm{p}<.05)$. It is evident from inspection of Fig. 2 that the shifted groups behaved quite differently from the nonshifted groups; in addition to exhibiting greater spontaneous recovery following a $24 \mathrm{~h}$ interruption, they subsequently show orderly progress toward extinction while the nonshifted groups do not. The more rapid extinction of the shifted groups may be readily explained in terms of generalization decrement-a habit weaker than the one originally acquired is being extinguished. The differences in amount of spontaneous recovery are not so readily interpretable unless one assumes the disappearance during the $24 \mathrm{~h}$ intersession interval of generalized, and therefore weaker, competing responses which were established in acquisition and persisted through the first 40 extinction trials. Such an interpretation attracts some validity from the realization that Day 4 is the first day the animals did not begin the daily session having to cope with the effects of the UCS. This change could have combined with the switch in CS intensity in the shifted groups to differentially weaken the competing responses (struggling in the chair, etc.) conditioned to the general surround and thus provide the illusion of greater spontaneous recovery.

\section{REFERENCES}

GRICE, G. R., \& HUNTER, J. J. Stimulus intensity effects depend upon the type of experimental design. Psychol. Rev., 1964, 71, 247-256.

HILGARD, E. R., \& MARQUIS, D. G. Conditioned eyelid responses in monkeys, with a comparison of dog, monkey, and man. Psychol. Monogr., $1936,47,186-198$

MOURANT, R. R. Eyelid conditioning in monkeys as a function of the intensity of the conditioned stimulus. Unpublished masters thesis, University of Florida, 1965.

PENNYPACKER, H. S., KING, F. A., ACHENBACH, K. E., \& ROBERTS, L. An apparatus and procedure for conditioning the eyeblink reflex in the squirrel monkey.J. exp. Anal. Behav., 1966, 9, 601-604.

PENNYPACKER, H. S., \& COOK, W. A. Acquisition and extinction of the conditioned eyelid response in the squirrel monkey as functions of the CS-UCS interval. Psychol Rep., 1967, 20, 1235-1243.

SOKOLOV, E. N. Perception and the conditioned reflex. New York: Pergammon Press, 1963.

\section{NOTES}

1. This report was adapted from a Masters thesis prepared by the first author under the direction of the second author. Any correspondence should be addressed to H. S. Pennypacker. This research was jointly supported by United States Public Health Service Grants MH-08887 and HE-06379, the latter a Primate Facilities Support Grant under the direction of A. F. Moreland, D.V.M. We thank David L. Remington for his assistance with the surgical preparation of the animals.

2. Now at North American Aviation, Columbus, Ohio. 